\title{
A IMPORTÂNCIA DO PLANEJAMENTO E CONTROLE DE PRODUÇÃO PARA AS INDÚSTRIAS DE CONFECÇÕES DA CIDADE DE MARINGÁ-PR: A PERSPECTIVA DOS GESTORES DE PRODUÇÃO
}

\section{THE IMPORTANCE OF PLANNING AND PRODUCTION CONTROL FOR THE GARMENT INDUSTRIES OF THE CITY OF MARINGA-PR: THE PERSPECTIVE OF THE PRODUCTION MANAGERS}

\author{
Paula Piva Linke ${ }^{1}$; Carlos Jaelso Albanese Chaves $^{2}$; Pedro Guena Espinha ${ }^{3}$; Fernanda Tsukuda ${ }^{4}$; \\ Vera Lúcia Salinas Narciso ${ }^{5}$ \\ ${ }^{1}$ Universidade Estadual de Maringá - UEM - Maringá - Brasil \\ paulapivalinke@gmail.com \\ ${ }^{2}$ Universidade Estadual de Mato Grosso do Sul - UEMS - Ponta Porã - Brasil \\ Jaelso@uems.br \\ ${ }^{3}$ Universidade Federal do Paraná - UFPR - Curitiba - Brasil \\ pedro.espinha@pucpr.br \\ ${ }^{4}$ Centro Universitário de Maringá - Cesumar - Maringá - Brasil \\ ferzinha_usa@hotmail.com \\ ${ }^{5}$ Centro Universitário de Maringá - Cesumar - Maringá - Brasil \\ verasalinas@hotmail.com
}

\begin{abstract}
Resumo
Este artigo objetivou conhecer e compreender a importância do Planejamento e Controle de Produção - PCP, pela perspectiva dos gestores de produção de indústrias de confecções da Cidade de Maringá-PR. Mais especificamente, compreender nos relatos dos entrevistados a importância do planejamento e do controle para o sistema produtivo, a conformidade do planejamento e do controle de produção com os objetivos organizacionais, e se os objetivos são bem definidos e se são alcançados em função da sua relação com o controle e o planejamento. A metodologia encontra-se inserida no método qualitativo de investigação. Para tanto, procurou-se com a abordagem qualitativa aprofundar-se no mundo dos significados das ações e relações humanas e descobrir através da análise do discurso uma realidade organizacional vivenciada pelos atores envolvidos a ela. Os resultados apresentaram que a compreensão sobre a função e os limites de atuação do PCP encontra-se um pouco limitada. Percebeu-se que os gestores conhecem a importância do Planejamento e Controle de Produção, mas ao mesmo tempo, possuem algumas lacunas a serem preenchidas, em relação a aspectos de planejamento e controle da produção. Por fim, este estudo evidenciou que, mais conhecimento [técnico e conceitual] para as organizações de médio porte, poderia melhorar sua competitividade, tornando-se mais eficiente em relação à produção.
\end{abstract}

Palavras-chave: planejamento de produção; controle de produção; manufatura. 


\section{Introdução}

Em função da grande competitividade de mercados, as empresas de pequeno e médio porte, particularmente as indústrias de confecções, estão tendo que se adequar a uma nova realidade: a necessidade de melhorar continuamente sua gestão de produção. A globalização dos mercados se torna uma força propulsora para a necessidade da melhoria contínua dos processos produtivos.

Tratando-se de processos produtivos em um ambiente altamente competitivo, a atenção das organizações se volta para a administração de operações, que segundo Krajewski, Ritzman, e Malhotra (2009) se refere ao projeto, direção e controle dos processos que transformam insumos em serviços e produtos. Para esses autores, uma organização é tão eficaz quanto seus processos.

Observa-se que, as indústrias de confecções mais preocupadas com os processos produtivos, em atendimento as necessidades organizacionais, instituem um setor específico que se preocupa, de forma geral, com o sistema produtivo, denominado planejamento e o controle da produção - PCP. Isto se deve ao fato do PCP se relacionar com os diversos setores organizacionais e possuir várias funções importantes, entre as quais a tomada de decisão de produção e o fornecimento de informações para se estabelecer as estratégias organizacionais. O PCP auxilia o bom funcionamento da produção, é por meio dele que o sistema produtivo é ajustado para atender as necessidades do setor de vendas. Portanto, o PCP não deve ser tratado de forma isolada, deve estar alinhado com os demais setores da empresa, para que a mesma seja capaz de alcançar suas metas e objetivos.

Considerando que o PCP atua por meio do intercâmbio de dados entre os mais variados departamentos da empresa, a problemática dessa pesquisa fundamenta-se na seguinte questão: Como os gestores de produção das indústrias de confecções de Maringá compreendem a importância do planejamento e controle de produção? Tendo por objetivo conhecer e compreender a importância do planejamento e controle da produção pela perspectiva dos gestores de produção das indústrias de confecções de Maringá.

Esta análise torna-se importante na medida em que fornece uma visão acerca da percepção dos gestores de produção, em pequenas e médias organizações, contribuindo para o entendimento e aperfeiçoamento do sistema produtivo de pequenas e médias empresas no setor de confecção.

\section{Planejamento e controle da produção: PCP}

Uma empresa tem como principal função, atender seus clientes. Para que isso seja possível é preciso que o trabalho desempenhado por seus colaboradores esteja em perfeita harmonia, ou seja, a empresa precisa estar organizada em setores, para que assim, as tarefas sejam desempenhadas de maneira correta e harmoniosa. Martins e Laugeni (2006, p. 211) afirmam que "a estratégia da manufatura é um conjunto de decisões visando atingir desempenho em critérios competitivos 
alinhados aos objetivos da empresa". Tratando-se da administração de produção se faz necessário apresentar o conceito de Ballestero-Alvarez (2001, p. 363-364):

Cabe à administração da produção buscar, definir e aplicar as ferramentas, instrumentos, métodos e alternativas que lhe proporcionem respostas para as seguintes perguntas: como, quando, quanto, com o que produzir? Os sistemas de produção existem, justamente, para auxiliar os executivos dessa área no processo de tomada de decisão.

Conforme Martins e Laugeni (2006) as atividades desenvolvidas por uma empresa, na tentativa de transformar insumos em produtos ou serviços, visam atender aos objetivos de curto, médio e longo prazo. Sendo que, essas atividades se inter-relacionam, muitas vezes de forma extremamente complexa e que o objetivo da administração da produção encontra-se na gestão eficaz dessas atividades. Para Davis, Aquilano e Chase (2001, p. 24) a "administração da produção pode ser definida como o gerenciamento dos recursos diretos que são necessários para a obtenção dos produtos e serviços de uma organização".

Para uma gestão eficaz a empresa deve ser composta por setores que se relacionam, fazendo com que os processos de produção, administração e vendas trabalhem de forma sinérgica, formando assim, todo um ciclo de produção. Dentre estas atividades destaca-se o PCP, sendo este o responsável pela programação e controle de produção (REIS, 1978). Para Martins e Laugeni (2006, p. 213) o PCP é "um sistema de transformação de informações, pois recebe informações sobre estoques, vendas previstas, linha de produtos, produção e capacidade produtiva. O PCP tem como incumbência transformar estas informações em ordens de fabricação", para esses autores o PCP é uma área de decisão da manufatura cujo objetivo corresponde tanto ao planejamento como ao controle dos recursos do processo produtivo. Os autores afirmam ainda, que as decisões tomadas no sistema afetam a competitividade da empresa, repercutem no desempenho percebido pelo cliente e afetam o desempenho da manufatura, devendo ser gerenciadas de maneira a suportar a estratégia competitiva da empresa.

Barreto (1997) refere-se ao PCP como o setor responsável por administrar de maneira correta os insumos: mão de obra, máquinas e equipamentos complementares, matérias primas, métodos e informações, sendo assim, o PCP funciona como um regulador, distribuindo e organizando o processo de fabricação. No entanto, mesmo funcionando como um regulador de insumos, o PCP, possui algumas limitações de recursos: limitações de custos, capacidade, tempo e qualidade, isso ocorre devido à complexidade do produto, sistema de produção e pelas próprias características da empresa (BARRETO, 1997; VOLLMANN et al, 2006).

É importante ressaltar que o PCP possui várias funções, dentre elas, programar e controlar a produção: determinar a quantidade a produzir, controlar os estoques, emitir ordens de produção, programar e movimentar as ordens de fabricação, acompanhar a produção e controlar a qualidade 
dos produtos (CHIAVENATO, 2005; RUSSOMANO, 2000; REIS, 1978; TUBINO, 2000; ZACARELI 1979).

Dias (2011, p. 5) afirma que “o PCP é o responsável pela programação e pelo controle do processo produtivo. [...] É um setor bastante específico e muito técnico, dependendo principalmente do tipo de processo". Para Chiavenato (2005) o PCP trabalha monitorando o processo produtivo e divide-se em quatro fases: projeto de produção, coleta de informações, planejamento e controle da produção.

\subsection{Projeto de produção}

O projeto de produção é a primeira fase do PCP, ele "procura definir como o sistema de produção deverá funcionar e quais as suas dimensões" (CHIAVENATO, 2005, p. 49). Para elaborar o projeto é necessário ter em mãos algumas informações que servem de base para atender as expectativas da empresa, entre as quais, pode-se citar o cruzamento entre estimativa de vendas e planejamento da produção, conforme afirma Reis (1978, p. 290):

Estimadas as vendas futuras e estabelecidos os níveis de capacidade produtiva e de estoque, trata-se de definir o projeto de produção para os próximos meses ou ano, dependendo do sistema produtivo e do produto fabricado, administrando a força de trabalho, o maquinário e o material necessário pra a fabricação do produto.

Sendo assim, “o PCP fará cruzamentos com a capacidade de produção, planejamento de vendas e pedidos em carteira, com objetivo de dar início à produção e projetar prazos de entrega" (BARRETO, 1997, p. 89). Além disso, Vollmann et al. (2006, p.34) afirmam que "os requisitos específicos para o projeto do sistema de PCP, dependem da natureza do processo de produção, do grau de integração da cadeia de suprimentos, das expectativas dos clientes e das necessidades da gerência”.

A partir do momento em que as informações foram analisadas é preciso coordenar corretamente a mão de obra, o maquinário e os materiais. Coordenar a mão de obra consiste em estabelecer quem faz o quê, como e onde, ou seja, direcionar a capacidade produtiva dos colaboradores para atingir os objetivos esperados. Administrar o maquinário refere-se a conhecer a capacidade produtiva de cada seção, assim como o número de máquinas e os equipamentos presentes na mesma. Controlar os materiais refere-se ao controle de estoque (almoxarifado), ou processos de requerimento do mesmo e ainda o controle do fluxo destes materiais dentro do processo produtivo (CHIAVENATO, 2005; TUBINO, 2000; RUSSOMANO, 2000; MACHLINE et al., 1990; HARDING, 1981; MARTINS e LAUGENI, 2006; BALLESTERO-ALVAREZ, 2001).

Por capacidade de produtiva entende-se que é a cadência máxima de produção de uma organização, considerando as variações diárias (como férias e ausências de funcionários) e os diferentes produtos e serviços (GAITHER e FRAZIER, 2008). De tal forma que, uma vez elaborado 
o projeto de produção, distribuem-se as funções, que são delegadas aos seus departamentos que interagem entre si para satisfazer suas necessidades e atingir as metas e os objetivos estabelecidos pela empresa. A partir deste momento inicia-se a próxima fase do PCP: a coleta de informações.

\subsection{Coleta de informações}

Quando se faz referência à segunda fase do PCP (a coleta de informações) é necessário conhecer a empresa, seus objetivos e capacidades. Sendo assim, Russomano (2000) afirma que o setor PCP precisa conhecer as necessidades de vendas e fazer com que todos os departamentos se movimentem para cumprir as solicitações de vendas. Devem conhecer detalhadamente o produto, as disponibilidades industriais, os recursos financeiros disponíveis para que a fabricação do mesmo seja possível e assim estabelecer um roteiro de produção.

Para Slack, Chambers, Johnston (2009) a coleta de informações é um sistema de cruzamento de dados, onde se busca uma visão detalhada das atividades produtivas e os demais setores da empresa e como estes se relacionam entre si. De outra maneira, é necessário obter informações de todos os setores, desde o administrativo até o produtivo, para que o PCP possa ser executado com sucesso. Chiavenato (2005, p. 50) complementa, afirmando que o PCP é um processo que canaliza e absorve informações, com propósito de permitir a tomada de decisões sobre o que fazer, quando e quanto fazer em termos de produção. À medida que tais informações são integradas, torna-se possível mobilizar máquinas e equipamentos, materiais e pessoas para o processo produtivo.

Percebe-se que, a coleta de informações serve de base para a elaboração do projeto de produção e para o planejamento de produção, assim como para o controle de todo o setor produtivo.

\subsection{Planejamento da produção}

Planejar é definir objetivos ou resultados a serem alcançados e definir meios que possibilite a realização de resultados desejados (MAXIMIANO, 2008). Para Daft (2010, p. 06) “o planejamento define onde a organização quer estar no futuro e como chegar lá. Planejar significa definir metas para o desempenho organizacional futuro e decidir sobre as tarefas e o uso dos recursos necessários". Maximiano (2008) observa que "o processo de planejamento é a ferramenta para administrar as relações com o futuro". Sendo assim, relaciona-se diretamente com o processo decisório das organizações.

O Planejamento da produção é um conjunto de ações inter-relacionadas que objetiva direcionar o processo produtivo da empresa e coordená-lo com os objetivos do cliente (POZO, 2010). Para este autor, o planejamento está envolto por duas etapas importantes dentro do processo, que são: a programação e o controle da produção. Referindo-se ao planejamento e controle da produção (PCP), Chiavenato (1991) observa-se que o planejamento de produção corresponde à uma fase do PCP e está diretamente relacionado à produção da empresa, ou seja, o que ela pretende produzir durante um determinado período. 
Juntamente com o planejamento surge à programação, que seria a determinação de como as atividades serão executadas em função do projeto e do planejamento. Referindo-se a programação Slack, Chambers, Johnston (2009) afirmam que a programação é compreendida por um trabalho complexo da administração da produção. Os programadores lidam com diversos tipos de recursos simultaneamente. As máquinas possuem diferentes capacidades e o pessoal apresenta diferentes habilidades.

Krajewski, Ritzman, e Malhotra (2009) observam que a programação é importante porque envolve uma quantidade enorme de detalhes e afetam todos os processos de uma organização. Afirmam que os processos de fabricação se beneficiam de técnicas de programação de demanda, da programação da força de trabalho e da programação das operações. No entender de Davis, Aquilano e Chase (2001), uma programação é uma distribuição temporal de atividades, utilizando recursos ou alocando instalações. Pozo (2010) ressalta que a programação é a fase intermediária entre o setor de planejamento e o setor de controle e observa que a programação se preocupa em determinar quando deverão ser executadas as operações.

Martins e Laugeni (2006, p.214) afirmam que "a programação da produção deve assegurar uma alta taxa de utilização das instalações e a sequência da programação dos produtos deve minimizar os tempos de setup". Segundo esses autores, uma vez definida as ordens de produção, essas devem ser sequenciadas na fábrica. Esse processo é conhecido por sequenciamento ou programação de chão de fábrica.

O PCP com capacidade finita apresenta como característica básica o fato de considerar a capacidade produtiva e as características tecnológicas do sistema produtivo como uma restrição dada a priori para a tomada de decisão da programação. O objetivo básico dessa premissa é garantir que o programa de produção desenvolvido seja visível dentro de uma capacidade disponível da empresa que está elaborando o planejamento. Portanto, é condição imprescindível que o sistema suporte simulações dos mais diversos tipos e que, ao mesmo tempo permita a modelagem de dados (BALLESTERO-ALVAREZ, 2001).

\subsection{Controle da produção}

Esta é a última fase do PCP, e é sem dúvida uma das mais importantes, pois fiscaliza todo o processo produtivo. Para Tubino (2000, p.26) “além de acompanhar a produção, o sistema de controle também está encarregado de coletar dados (índices de defeitos, horas/máquina, horas/homem, consumo de materiais, etc.) para outros setores do sistema produtivo". O controle existe para avaliar, corrigir e registrar dados do sistema produtivo, ele se encarrega de manter a produção dentro do que foi planejado e assegurar que os objetivos sejam atingidos (CHIAVENATO, 2005; CHIAVENATO, 1991; MARTINS e LAUGENI, 2006; BALLESTEROALVAREZ, 2001). 
Para Pozo (2010, p. 104) "a função do controle, como parte integrante do sistema de planejamento é fazer a avaliação das ações que estão sendo desenvolvidas no processo produtivo e compará-las com o planejado". Daft (2010) observa que controlar denota monitorar as atividades dos funcionários, determinar se a organização está na direção das suas metas, fazendo correções se necessário.

Então, nota-se que o controle da produção abrange vários setores da empresa, não apenas a montagem do produto ou o chão de fábrica. O controle deve iniciar na compra da matéria prima e acompanhar o produto até a sua eventual colocação no estoque, loja e entrega ao representante ou cliente. Neste caso, o controle possui a finalidade fiscalizar todos os processos e cruzar os dados e informações referentes à produção, verificando se as atividades planejadas estão sendo executadas de maneira satisfatória e se necessário deve-se fazer ajustes (SLACK; CHAMBERS; JOHNSTON, 2009). Barreto (1997, p. 91) afirma ainda que, “a importância do PCP está em ser o elo entre os diversos setores ou departamento de uma empresa". Este autor cita como exemplo o relacionamento do PCP com outros setores da indústria da confecção: Produto; Modelagem; Produção; Controle de Estoque; Expedição e faturamento; e Vendas.

Contudo, de acordo com o percurso teórico, o sucesso do sistema produtivo depende do relacionamento entre as funções básicas, que são desempenhadas por diversos setores da empresa. Tais funções devem interagir entre si, bem como, deve haver uma constante troca de informações para que o sistema trabalhe corretamente, alcançando assim, o desempenho ideal.

\section{Metodologia}

Esta pesquisa compreende os métodos qualitativos de investigação. Para Stablein (2001) as pesquisas de cunho mais qualitativo visam descobrir e comunicar uma realidade organizacional na maneira como ela é vivenciada pelos vários atores envolvidos, ou que encontra-se compatível com as intenções do estudo. Porém, um estudo qualitativo procura analisar detalhadamente os significados e características situacionais apresentadas pelos entrevistados, buscando compreender a realidade apresentada por meio das entrevistas. Conforme May (2004) o método de entrevista é utilizado para gerar ou manter conversações com pessoas sobre um tópico específico ou um leque de tópicos e que as entrevistas geram compreensões ricas a respeito das experiências, opiniões, valores, aspirações, atitudes e sentimentos de pessoas.

A coleta de dados deste trabalho foi realizada por entrevistas com gestores de produção de indústrias têxteis [de médio porte] da Cidade de Maringá do estado do Paraná. O primeiro entrevistado, Sr. Tesarolo é formado em administração de empresas e trabalha há mais de 12 anos com atividades relacionadas ao PCP. O segundo entrevistado Sr. Pires, não concluiu o terceiro grau, mas possui conhecimentos na área de PCP oriundos de uma experiência de 11 anos. O terceiro 
entrevistado, o Sr. Sampaio, também formado em administração de empresas, é o que possui o menor tempo de experiência com o planejamento e controle de produção, mesmo assim, trabalha há oito anos com o PCP. A experiência dos entrevistados pode conceber a confiabilidade nos resultados dessa pesquisa. A análise dos dados, foi realizada por meio da análise do discurso, uma vez que se utilizou a técnica de entrevista para se obter os dados.

No âmbito deste trabalho o discurso foi compreendido, como construções ideológicas e sociais contidas no texto (enquanto materialização da fala), o que possibilita visualizar, no corpus de entrevistas, a produção de sentidos, das práticas de gestão da produção da indústria de confecções, na visão dos atores que estão envolvidos a ela. Orlandi (2005) ressalta que, que o gesto do analista é determinado pelo dispositivo teórico enquanto que o gesto do sujeito por um dispositivo ideológico.

\section{Resultados e discussão}

Ao se iniciar a entrevista, os sujeitos envolvidos com a pesquisa comentaram sobre a importância de se ter um sistema produtivo bem planejado e controlado. Todos os entrevistados relataram que o planejamento e o controle das atividades produtivas são importantes, sendo que, o primeiro entrevistado, Sr. Tesarolo relacionou o planejamento e o controle ao atendimento dos prazos e que com o PCP o gestor pode estimar o prazo de entrega dos produtos aos clientes. O segundo entrevistado o Sr. Pires, relatou que a falta de planejamento e de controle resulta em erros, o que dificulta o atendimento dentro do prazo pré-estabelecido e ainda, mencionou a importância do controle para a gestão da mão de obra, uma vez que a mão de obra não pode ser ociosa e nem faltar. O Sr Sampaio, terceiro respondente, salientou a importância do controle para se atingir o objetivo da organização e que no planejamento se estabelece as metas e objetivos.

É importante sim, o nosso caso de empresa, a gente consegue planejar todas as entregas dos nossos pedidos em função do PCP, todo nosso controle de produção. A gente consegue estimar qual é o prazo de entrega e quais as quantidades que a gente pode estar absorvendo [relato de entrevista - Tessarolo].

Eu acredito que sim, por que se você não controlar e não planejar, você erra de várias maneiras, se você não controlar na quantidade de peças produzidas, você pode errar na quantidade de funcionários, da mão de obra, então, se você não planejar, às vezes você não consegue entregar o seu pedido ou às vezes sobra mão de obra [relato de entrevista Pires].

Com certeza, em uma empresa bem planejada, todo controle e toda a produção você consegue enxergar o seu objetivo. Na hora que o planejamento é montado, você cria as metas e os objetivos, então você sabe aonde você quer chegar, com certeza ele tem a necessidade de ser bem controlado mesmo, para que os objetivos sejam atendidos [relato de entrevista - Sampaio]. 
Vale ressaltar que o PCP possui várias funções, além de prestar um atendimento ao setor de vendas, ele se torna responsável pela programação e controle da produção como um todo, determinando a quantidade a produzir, controlando estoques, emitindo ordens de produção, e de fabricação, acompanhando a produção e controlando a qualidade dos produtos. Assim, considerando as funções do PCP e sua relação com o setor de vendas, percebe-se uma estreita relação com o volume de produção e aos prazos pré-estabelecidos com os clientes.

Tal relação, se apresentada na fala dos entrevistados, o que corrobora com as palavras de Harding (1981), uma vez que, um dos objetivos do planejamento de produção encontra-se em satisfazer as datas de entrega aos clientes, por meio do planejamento de sequência das atividades de produção. Vale salientar a informação de Barreto (1997) quando afirma que a importância do PCP está em ser o elo entre os diversos setores ou departamentos de uma empresa. Nota-se que essa inter-relação entre os diversos setores organizacionais é importante para se atingir os objetivos organizacionais, o que foi ressaltado pelo terceiro entrevistado. Vale observar que as decisões tomadas no sistema podem afetar diretamente a competitividade e o desempenho e que devem ser gerenciadas de maneira a suportar a estratégia competitiva da empresa.

Foi questionado se a organização possui seus objetivos claros e bem definidos, e ainda, descritos de forma que possibilite aos funcionários conhecerem os rumos dessa organização. Todos os entrevistados responderam de forma positiva. $\mathrm{O}$ primeiro entrevistado mencionou $\mathrm{o}$ planejamento anual e o regimento interno, mas não comentou sobre o estabelecimento dos objetivos organizacionais. O segundo apresentou a importância das informações para se obter os resultados, e o terceiro entrevistado se referiu à importância de se falar dos objetivos organizacionais e mencionou que as informações devem ser passadas nas reuniões para se atingir os objetivos.

Sim, nós temos um planejamento anual de produção, nós temos o nosso regimento interno muito bem definido, junto com o nosso organograma da empresa, com todas as funções. Nós montamos a descrição dos cargos de todos os funcionários, o procedimento operacional padrão, o que é que ele faz desde o momento em que ele chega à empresa até o momento que ele tem que sair [relato de entrevista - Tessarolo].

Sim, toda a empresa, tem que ter os objetivos bem definidos e os funcionários saberem disso. Só que na produção, eles têm que saber o quanto eles tem que produzir por dia. Temos a meta diária e a meta mensal, este é o objetivo deles e o objetivo de como anda a empresa no percurso comercial. Como está seu produto lá fora. Todas estas informações são divulgadas para os funcionários [relato de entrevista - Pires].

A organização tem seus objetivos, eles são claros, existem reuniões semanais entre a diretoria, toda a semana eles se reúnem, procuram os objetivos deles e passa para os gerentes, a informação é passada para os funcionários, logicamente não no seu contexto total. Mas eles sabem os nossos objetivos, sabem onde nos queremos chegar [relato de entrevista - Sampaio]. 
Vale lembrar que, na fase de coleta de informações, procura-se conhecer a empresa, seus objetivos, metas e capacidades. Compreendo isso e relacionando a coleta de informações aos relatos dos entrevistados, nota-se a afinidade entre o PCP e os objetivos organizacionais e percebe-se que, o segundo e o terceiro entrevistado compreendem que definir metas e objetivos é importante para dar rumo à organização e balizar as atividades do PCP. Vale lembrar que a estratégia da manufatura é um conjunto de decisões que visa atingir ao desempenho desejado alinhado aos objetivos da empresa.

Tratando-se do PCP e sua importância, foi perguntado se a organização procura estimar suas vendas futuras, todos responderam que realizam uma estimativa e que esta estimativa procura auxiliar no planejamento e controle de produção.

Sim. Com certeza. Temos uma estimativa de vendas, este ano algo em torno de $10 \%$ superior ao ano passado e você trabalha dentro de uma grade de produtos, um pacote de produtos, então nós estimamos a produção de acordo com as vendas do ano anterior e fazemos um planejamento para o ano todo. E assim, você trabalha com a programação em todos os setores, maquinário, produtividade individual e setorial [relato de entrevista Tessarolo].

A gente trabalha com uma forma de vendas programada, através de representante, então a gente faz uma programação, uma estimativa. Lógico baseado tanto nos representantes como na produção, então se tem a estimativa. A gente trabalha em cima das metas para os representantes que estimulam a produção mensal, se os representantes não venderem a gente tem quatro lojas que absorve a produção. A estimativa é utilizada sim, ela auxilia e ajuda no processo de planejamento [relato de entrevista - Pires].

Sim, nós estimamos as vendas futuras, hoje temos um planejamento de aumento de representantes, e isso vai fazer com que as nossas vendas fluem bem mais no futuro e isso também não é para o agora, é para o próximo ano, então eles já estão enxergando lá na frente [relato de entrevista - Sampaio].

Ballestero-Alvarez (2001) define o PCP como um sistema gerenciador dos processos produtivos e que tal sistema auxilia o gestor de produção, oferecendo-lhe todas as informações necessárias para que a administração da produção possa ser efetuada corretamente. Segundo as afirmações desse autor, o PCP não toma decisões, mas oferece subsídios para os níveis superiores. Portanto, percebe-se a importância do PCP para o alcance dos objetivos organizacionais. Referindose a importância do PCP em relação à estimativa de vendas da organização, Reis (1978) afirma que para definir o projeto de produção é necessário conhecer a força de trabalho o maquinário, o material necessário, e que para isso é importante se conhecer as vendas futuras e o estoque de materiais e produtos acabados.

Observa-se que o PCP faz cruzamentos entre a capacidade de produção e o planejamento de vendas, com objetivo de dar início à produção e projeção de prazos de entrega. Russomano (2000) lembra que o setor PCP precisa conhecer as necessidades de vendas e fazer com que todos os departamentos se movimentem para cumprir, as solicitações de vendas. Chiavenato (1991) menciona que o PCP deve ter em vista, a capacidade produtiva e a previsão de vendas que deve ser 
atendida. Sendo assim, afirma-se que, para o PCP gerar informações são necessárias várias outras informações, entre elas, a capacidade produtiva e a estimativa de vendas. Fica evidenciado nos relatos que os sujeitos dessa pesquisa conhecem a importância da estimativa de vendas futuras e que essa estimativa é uma informação necessária para a administração de a produção obter bons resultados.

Percebendo que os entrevistados [gestores de produção], reconhecem a importância do planejamento, programação e o controle de produção, questionou-se como se constitui o planejamento de produção das organizações em estudo. O primeiro entrevistado relacionou a pergunta ao controle, mencionando o controle de estoques mínimos, o controle dos lotes como sendo realizado de forma sequencial. O Sr Pires detalhou mais e comentou sobre o planejamento inicial, relacionando este às vendas, afirmando que organiza lotes de produção, planeja as compras de materiais e emite as ordens de produção, por último mencionou que acompanha todas as datas e a capacidade produtiva, referindo-se ao controle. O terceiro entrevistado também relacionou a questão as vendas a aos lotes de cada produto.

\begin{abstract}
Nós temos estoques mínimos para controle de produção para dos produtos de maior consumo. Todos os nossos pedidos geram uma ordem de produção inicial [que é o início da produção], então todos os pedidos vão estar entrando no processo, mesmo que seja para substituir o estoque mínimo ou para estar gerando o processo completo. Então ele funciona da seguinte forma: matando pedidos, por etapas, passando pelo período da tecelagem, tinturaria, almoxarifado, corte, estamparia, costura, a gente acompanha todo o processo nessa sequência [relato de entrevista - Tessarolo].
\end{abstract}

\begin{abstract}
A primeira etapa do planejamento vem pelo pedido que você vendeu, então a gente recebe os pedidos, abre em lotes de produção com data final de entrega. Depois é feito o pedido de corte, planejamento de compras, consequentemente solta as ordens de produção, fazendo o fechamento na data de entrega. Quando já está tudo planejado a gente se prepara para soltar o corte e a produção, sempre de olho nas datas de entrega e na capacidade produtiva de cada linha e modelo [relato de entrevista - Pires].
\end{abstract}

Hoje, nosso planejamento de PCP se constitui em um setor de três pessoas e ele se desenvolve com análise. Hoje nós temos uma produção que é calculada de acordo com a venda realizada para cada produto. Estas pessoas trabalham em cima de vendas. Conforme saem às vendas eles vão analisando a produção, e verifica-se o que vai poder soltar, de produção, de modelo a modelo [relato de entrevista - Sampaio].

Enquanto Chiavenato (2005) divide o planejamento da produção em três fases: formulação do plano de produção, implementação do plano de produção por meio da programação de produção e execução do plano de produção por meio de emissões de ordens, outros autores acrescentam o roteiro, o aprazamento e a liberação. Harding (1981) afirma que o objetivo do planejamento de produção é satisfazer as datas de entrega aos clientes com o mínimo custo total, por meio do planejamento de sequência das atividades de produção. Nota-se que, considerar o PCP apenas em função do aprazamento é uma condição um pouco limitada. Harding (1981) menciona o controle dos custos e o sequenciamento das atividades produtivas, relacionando-a a capacidade de produção. Desta forma, o planejamento se constitui de algumas fases, sendo que a entrega no prazo pré- 
estabelecido é o objetivo final. Percebe-se que, apenas o segundo entrevistado apresentou como o planejamento de sua organização é constituído. Ademais, nota-se que o primeiro entrevistado não compreende a abrangência da função do planejamento na mesma proporção que os outros dois respondentes da pesquisa, ou seja, este entrevistado [Sr Tessarolo] não observa a produção de forma integrada às vendas, limitando-se ao controle de estoques.

Perguntou-se aos respondentes como a programação de produção é desenvolvida na organização. O primeiro entrevistado falou a respeito da avaliação setorial e de sua capacidade. $\mathrm{O}$ segundo respondente afirmou que a programação é realizada com base no planejamento e que depende de vários setores, o que exige um acompanhamento, referindo-se ao controle e disse ainda que, de nada adianta planejar se não controlar. $O$ terceiro relacionou a programação ao planejamento, as vendas e a capacidade produtiva.

Nós avaliamos todos os setores e a capacidade setorial, nosso planejamento primeiro, vai de acordo com o setor, alguns produtos exigem mais de alguns setores do que os outros [relato de entrevista - Tessarolo].

Ela é desenvolvida através do planejamento e o desenvolvimento, dela depende dos setores de corte, vedas e compras e estoque, ai você faz o acompanhamento, é preciso fazer o acompanhamento de suas ordens, fazer com que elas sejam executadas de maneira correta para que tudo esteja pronto na hora certa para o faturamento [relato de entrevista - Pires].

A programação trabalha em cima do planejamento. E a programação é determinada pelos prazos de vendas e a quantidade junto com a capacidade produtiva [relato de entrevista Sampaio].

Considera-se que a programação envolve detalhes que afetam todos os processos de uma empresa, uma vez que, para se programar a produção, determina-se quando deverão ser realizadas as tarefas e operações de produção e quando deverá ser feito. Portanto, programar produção é estabelecer uma agenda de compromissos para as diversas seções envolvidas no processo produtivo. Para Martins e Laugeni (2006) a programação da produção deve assegurar uma alta taxa de utilização das instalações, sendo que, uma vez definida as ordens de produção, essas devem ser sequenciadas na fábrica. Percebe-se que os entrevistados não relacionaram a programação aos compromissos das seções produtivas ou ao sequenciamento das operações. Confirma-se uma falta de compreensão por parte dos entrevistados sobre o significado da programação.

Compreendendo que todo planejamento necessita de um controle, foi questionado sobre a importância do controle para a organização. O Sr. Tessarolo relatou que a organização possui um sistema operacional que controla todos os setores e que esse sistema proporciona o acompanhamento de todo o processo. O Sr. Pires ressalvou que o controle é um dos fatores mais importantes da produção. O terceiro entrevistado, disse que o controle é essencial, que sem o controle não há como a produção fluir e que a organização possui um sistema que controla todo o processo. 
Nós temos, junto com o controle, um sistema operacional que trabalha em todos os setores da empresa. Todas as movimentações são gerenciadas e a gente consegue acompanhar todo o processo. Sabemos se em algum momento ele está falho ou não, se ele está cumprindo com a data de acordo com o planejamento que foi feito anteriormente [relato de entrevista - Tessarolo].

O controle é um dos fatores mais importantes da produção. Se você não controla você não consegue saber o que você tem no meio da produção, o que você tem no corte e o que você tem no pátio. [relato de entrevista - Pires].

O controle é essencial, o controle faz parte do PCP, sem o controle não tem como a empresa fluir. Precisa ser muito bem feito e bem controlado, o nome já diz tudo, precisa ter uma pessoa ali, que cuide de tudo, que vai atrás, que corre, pegue os lotes e faça-o andar da melhor forma possível. Hoje nós temos um software específico que controla toda a rota de produção [relato de entrevista - Sampaio].

Para Slack, Chambers, Johnston (2009) o controle da produção abrange vários setores da empresa, não apenas a montagem do produto ou o chão de fábrica. O controle deve iniciar na compra da matéria prima e acompanhar o produto até a sua eventual colocação no estoque, loja e entrega ao representante ou clientes. Neste caso, o controle tem por finalidade fiscalizar todos os processos e cruzar os dados referentes à produção e ao plano de produção, verificando se as atividades planejadas estão sendo executadas de maneira adequada e se ajustes são necessários. Todos os entrevistados compreendem que o acompanhamento da produção é importante e que o controle é fundamental para se conseguir atingir os objetivos, os entrevistados não citaram o sequenciamento, porém percebe-se que existe o controle das ordens de produção.

Foi indagado, se os entrevistados acreditam que o controle desenvolvido pela organização consegue corrigir os possíveis desvios do sistema produtivo. O primeiro entrevistado mencionou que é para isso mesmo que existe o controle, $\mathrm{O}$ segundo entrevistado comentou que o erro deve ser reparado imediatamente senão atrapalha a fila de produção. E terceiro entrevistado, afirmou que é através do controle que se busca corrigir erros e compensar algum prejuízo. A função dele é corrigir estes erros. Então, acompanhando você sabe se está de acordo
com o prazo ou não [relato de entrevista - Tessarolo].

Sim. Sempre que ocorre um erro ele tem que ser informado imediatamente, para que se possa soltar um outro corte, uma outra ordem pra corrigir, sejam menos peças, ou seja, o lote inteiro, mas este erro não pode deixar de ser corrigido, tem que ser rápido se não você atrapalha a sua fila de produção [relato de entrevista - Pires].

O controle, assim que você verifica e acha algum erro no sistema, no processo, a gente busca corrigir o erro e compensar o prejuízo para tentar recuperar o tempo perdido [relato de entrevista - Sampaio].

O controle existe para avaliar, corrigir e registrar dados do sistema produtivo, se encarregando de manter a produção dentro do que foi planejado e assegurar que os objetivos sejam atingidos. Analisando os relatos dos entrevistados, observa-se que eles relacionam o controle apenas com as falhas, mas deve-se considerar que o controle é essencial para se evitar os erros e atender ao planejamento. Nenhum dos entrevistados relacionou o controle ao planejamento da produção, o 
que pode apresentar certa limitação na compreensão da importância do controle dentro das atividades do PCP.

A pesquisa contemplou ainda a seguinte questão: Qual a relação que você faz entre controle produtivo e objetivos organizacionais? Todos comentaram que o controle é importante para se atingir os objetivos da organização.

Os objetivos organizacionais têm que estar bem definidos, para você poder cumprir uma meta. Já o controle produtivo, é você acompanhar e ver se a meta está sendo atingida, se você não tiver um controle organizacional, você não vai conseguir atingir estas metas [relato de entrevista - Tessarolo].

A relação do controle produtivo e dos objetivos acontece quando você tem um controle efetivo e bem acompanhado. Os seus objetivos vão ser alcançados por que o maior objetivo além da qualidade é a pontualidade na entrega [relato de entrevista - Pires].

O PCP analisa e vê o que pode ser feito para atingir os objetivos [relato de entrevista Sampaio].

Analisando as respostas dos entrevistados, percebe-se a compreensão da importância do controle, o que se aproxima dos conceitos apresentados por Chiavenato (2005); Martins e Laugeni, (2006); Ballestero-Alvarez, (2001) ao mencionarem que o controle existe para avaliar, corrigir e registrar dados do sistema produtivo, ele se encarrega de manter a produção dentro do que foi planejado e assegurar que os objetivos sejam atingidos.

Por último, foi verificado se nas empresas que eles (os entrevistados) trabalham atingem as metas e os objetivos pré-estabelecidos.

Sim, acredito que estamos atendendo a maioria deles [relato de entrevista - Tessarolo].

Eu acredito que atinge sim. Você tem que ter uma meta traçada, trimestral, anual e atingir as suas metas em todos os setores, o primeiro passo é o planejamento depois vem o acompanhamento e terceiro ver se você vai fechar o pedido e entregar no prazo. E se você produzir direito à organização vai atingir suas metas e vai ter lucro [relato de entrevista Pires].

Com certeza, por que eles fazem todo um planejamento a ser cumprido anualmente, e se houver problemas é feito um remanejamento das atividades para que os objetivos possam ser obtidos. E o PCP é fundamental nesta parte, por que sem a produção, não se atinge objetivos, não se tem dinheiro pra investir [relato de entrevista - Sampaio].

Os entrevistados relatam o alcance das metas e objetivos organizacionais. Porém esse alcance pode ser limitado, por compreenderem em partes a importância e os limites de atuação do PCP. Essa constatação deve-se a não conformidade apresentada em relação a alguns conceitos, durante o processo de análise. Tubino (2000) afirma que o PCP é responsável pela coordenação e aplicação de recursos produtivos de forma a atender da melhor maneira possível aos planos estabelecidos em níveis estratégico, tático e operacional. Chiavenato (2005) descreve que o PCP como é um processo que canaliza e absorve informações para permitir decisões sobre o que fazer, quando e quanto realizar em termos de produção. À medida que tais informações são integradas, torna-se possível mobilizar máquinas e equipamentos, materiais e pessoas para o processo 
produtivo. Compreendendo as afirmações dos autores que contribuem para esse estudo, percebe-se que a falta compreensão dos limites de atuação e de responsabilidades do PCP pode prejudicar o desempenho organizacional.

\section{Considerações finais}

Este artigo teve por objetivo conhecer e compreender a importância do planejamento e controle da produção na perspectiva dos gestores de produção das indústrias de confecções de Maringá-PR. Foi observado que os gestores de produção, que constituem os sujeitos dessa pesquisa, reconhecem a importância do planejamento e do controle de produção para se alcançar os objetivos organizacionais. Porém, foi observado em alguns pontos que a compreensão sobre a função e os limites de atuação do PCP encontra-se um pouco limitada. Em alguns questionamentos os entrevistados não apresentaram conhecimentos sobre a importância e a relação do PCP com os diversos setores da organização limitando assim a sua função e capacidade de interagir com o ambiente em prol dos objetivos organizacionais.

Reconhecer que é importante, mas não compreender alguns detalhes essenciais, tais como, a relação da programação e o sequenciamento das ordens de produção, pode gerar decisões que prejudicam o atendimento dos prazos pré-estabelecidos pelo setor de vendas. A compreensão sobre a importância do controle também se apresentou limitada na perspectiva dos gestores de produção.

Compreende-se, portanto, que os gestores conhecem a importância do PCP, mas ao mesmo tempo possuem algumas lacunas em relação a aspectos pontuais de planejamento e controle da produção. Considerando que o PCP é responsável pela coordenação e aplicação de recursos produtivos de forma a atender da melhor maneira possível aos planos pré-estabelecidos, as indústrias em questão, poderiam estabelecer novos objetivos e metas em função de uma maior compreensão por parte dos profissionais que atuam no planejamento e controle do setor produtivo. Em outras palavras, nota-se que, mais conhecimento [técnico e conceitual] para as organizações de médio porte, poderia melhorar sua competitividade, tornando-se mais eficiente em relação à produção.

\footnotetext{
Abstract

This article aimed to know and understand the importance of Production Planning and Control CFP, from the perspective of the managers of garment production industries of the city of MaringáPR. More specifically, the reports of the respondents understand the importance of planning and control to the production system, the conformity of the planning and production control with organizational objectives, and goals are well defined and are made on the basis of their relationship with the control and planning. The methodology is included in the qualitative research method. To this end, we sought to deepen the qualitative approach to the world of actions and meanings of human relationships and discover through a discourse analysis of organizational reality experienced by the actors involved with it. The results showed that the understanding of the role and limits of
} 
action of PCP is somewhat limited. It was felt that managers know the importance of Production Planning and Control, but at the same time, have some gaps to be filled in relation to aspects of planning and production control. Finally, this study showed that more knowledge [technical and conceptual] for midsize organizations, could improve its competitiveness by becoming more efficient in terms of production.

Key-words: production planning; production control; manufacturing.

\section{Referências}

BALESTERO-ALVAREZ, Maria E. Administração da qualidade e da produtividade: abordagem do processo administrativo. São Paulo: Atlas, 2001.

BARRETO, Antônio Amaro M. Qualidade e produtividade na indústria da confecção: uma questão de sobrevivência. Londrina: Impressão Midiograf, 1997.

CHIAVENATO, Idalberto. Administração de materiais: uma abordagem introdutória. Rio de Janeiro: Elsevier, 2005 .

CHIAVENATO, Idalberto. Iniciação a administração de materiais. São Paulo: Makron, McGraw-HILL, 1991.

DAFT, Richard L. Administração. AVRITCHER, Harue Ohara (trad.). São Paulo: Cengage Learning, 2010.

DAVIS, Mark M.; AQUILANO, Nicholas J. e CHASE, Richard B. Fundamentos da administração da produção. São Paulo: Bookman, 2001.

DIAS, Marco Aurélio P. Administração de materiais: princípios, conceitos e gestão. São Paulo: Atlas, 2011.

GAITER, Norman e FRAZIER, Greg. Administração da produção e operações. São Paulo: Cengage Learning, 2008.

HARDING, Alan Hamish. Administração da produção. São Paulo: Atlas, 1981.

KRAJEWSKI, Lee J.; RITZMAN, Larry e MALHOTRA, Manoj. Administração de produção e operações. São Paulo: Pearson Prentice Hall, 2009.

MACHLINE, Claude; MOTA, Ivam de Sá; GANGSCHOEPS, Wolf; WEIL, Kurte. Manual de administração de produção. $9^{\circ}$ ed. Rio de Janeiro: Editora da Fundação Getúlio Vargas, 1990.

MARTINS, Perônio G., LAUGENI, Fernando P. Administração da produção. $2^{\circ}$ ed, São Paulo: Saraiva, 2006.

MAY, Tim. Pesquisa social: questões, métodos e processos. Porto Alegre: Artmed, 2004.

MAXIMIANO, Antonio Cesar Amaru. Introdução à administração. $7^{a}$ ed. São Paulo: Atlas, 2008.

ORLANDI, Eni P. Discurso e texto: formulação e circulação dos sentidos. Campinas, SP: Pontes, 2005.

POZO, Hamilton. Administração de recursos materiais e patrimoniais: uma abordagem logística. São Paulo: Atlas, 2010.

REIS, Dayr Ramos Américo dos. Administração da produção: sistema, planejamento, controle. São Paulo: Atlas, 1978.

RUSSOMANO, Victor Henrique. Planejamento e controle da produção. $6^{\circ}$ ed. São Paulo: Pioneira, 2000.

SLACK, Nigel; CHAMBERS, Stuart e JOHNSTON, Robert. Administração da produção. São Paulo: Atlas, 2009.

STABLEIN, Ralph. Dados em estudos organizacionais. In: CLEGG, Stewart R.; HARDY, Cynthia; NORD, Walter R. (Org) / CALDAS, Miguel; FACHIN, Roberto; FISCHER, Tânia (Org. Bras.). Handbook de estudos organizacionais: reflexões e novos direcionamentos. Vol. II. São Paulo: Atlas, 2001. 
TUBINO, Dalvio Ferrari. Manual de planejamento e controle da produção. São Paulo; Atlas, 2000.

VOLLMANN, Thomas .E; BERRY, William . L; WHYBARK, Clay .D; JACOBS, Robert. F. Sistema de planejamento e controle da produção para gerenciamento da cadeia de suprimentos. $5^{\circ}$ ed. Porto Alegre: Bookman, 2006.

ZACCARELLI, S. Batista. Programação e controle da produção. $5^{\circ}$ ed. Rer. São Paulo: Pioneira, 1979.

\section{Dados dos autores:}

Nome completo: Paula Piva Linke

Filiação institucional: UEM - Universidade Estadual de Maringá

Departamento: Programa de Pós-graduação em História (PPH)

Função ou cargo ocupado: Mestranda- Bolsista

Endereço completo para correspondência: Rua São João 200 Ap 43, Zona Sete, Maringá, Paraná, CEP: 87030200

Telefones para contato: (44) 99896461

e-mail:paulapivalinke@gmail.com

\section{Nome completo: Carlos Jaelso Albanese Chaves}

Filiação institucional: UEMS - Universidade Estadual de Mato Grosso do Sul

Departamento: Ciências Contábeis

Função ou cargo ocupado: Professor

Endereço completo para correspondência: Av. Marechal Floriano 567 Centro, Ponta Porã, Mato

Grosso do Sul, Brasil. CEP: 79900-000

Telefones para contato: (67) 8168-1002

e-mail: jaelso@uems.br

Nome completo: Pedro Guena Espinha

Filiação institucional: UFPR - Universidade Federal do Paraná

Departamento: Administração

Função ou cargo ocupado: Doutorando

Endereço completo para correspondência: R. Goiânia, 650 Sobrado 7 - Cajuru - Curitiba-PR CEP: 82940-150

Telefones para contato: (41) 8810-4317

e-mail: pedro.espinha@pucpr.br

Nome completo: Fernanda Tsukuda

Filiação institucional: Sem filiação (Graduada) 
Departamento:

Função ou cargo ocupado:

Endereço completo para correspondência: Rua Assunção 158, Zona Sete, Maringá, Paraná, CEP: 87005-240

Telefones para contato: (44) 30294343

e-mail: ferzinha_usa@hotmail.com

Nome completo: Vera Lúcia Salinas Narciso

Filiação institucional: Sem filiação (Graduada)

Departamento:

Função ou cargo ocupado:

Endereço completo para correspondência: Rua Pioneiro Geraldo Tono, 317, Jardim Ouro Cola, Maringá, Paraná, CEP: 87070-160

Telefones para contato: (44) 30316133

e-mail: verasalinas@hotmail.com

Enviado em: 04/11/2011

Aprovado em: 07/07/2013 